\title{
Costs of different strategies for neonatal hearing screening: a modelling approach
}

\author{
H C Boshuizen, G J van der Lem, M A Kauffman-de Boer, G A van Zanten,
} A M Oudesluys-Murphy, P H Verkerk

TNO Prevention and Health, Division of Public Health, Leiden, The Netherlands H C Boshuizen

Dutch foundation of the Deaf and Hard of Hearing Child $G$ J van der Lem M A Kauffman-de Boer

Department of Audiology, Academic Hospital

Rotterdam/Sophia Children

Hospita1/Erasmus University Rotterdam, Rotterdam, The Netherlands

$\mathrm{G} A$ van Zanten

Department of Paediatrics, Medical Center

Rijnmond-Zuid, Location Zuider, Rotterdam

A M Oudesluys-Murphy

TNO Prevention and Health, Division of Child Health and Health Care, Leiden P H Verkerk

Correspondence to: Dr Boshuizen, National Institute of Public Health and the Environment, Computerisation and Methodological Consultancy Unit, PO Box 1, NL-3720

BA Bilthoven, The

Netherlands

Hendriek.Boshuizen $a$ RIVM.NL

Accepted 6 July 2001

\begin{abstract}
Objective-To compare the cost effectiveness of various strategies for neonatal hearing screening by estimating the cost per hearing impaired child detected. Design-Cost analyses with a simulation model, including a multivariate sensitivity analysis. Comparisons of the cost per child detected were made for: screening method (automated auditory brainstem response or otoacoustic emissions); number of stages in the screening process (two or three); target disorder (bilateral hearing loss or both unilateral and bilateral loss); location (at home or at a child health clinic).

Setting-The Netherlands

Target population-All newborn infants not admitted to neonatal intensive care units.
\end{abstract}

Main outcome measure-Costs per child detected with a hearing loss of $40 \mathrm{~dB}$ or more in the better ear.

Results-Costs of a three stage screening process in child health clinics are $€ 39.0$ (95\% confidence interval 20.0 to 57.0 ) per child detected with automated auditory brainstem response compared with $€ 25.0$ (14.4 to 35.6) per child detected with otoacoustic emissions. A three stage screening process not only reduces the referral rates, but is also likely to cost less than a two stage process because of the lower cost of diagnostic facilities. The extra cost (over and above a screening programme detecting bilateral losses) of detecting one child with unilateral hearing loss is $€ 1500$ 4000. With the currently available information, no preference can be expressed for a screening location.

Conclusions-Three stage screening with otoacoustic emissions is recommended. Whether screening at home is more cost effective than screening at a child health clinic needs further study.

(Arch Dis Child Fetal Neonatal Ed 2001;85:F177-F181)

Keywords: costs; hearing; screening; otoacoustic emissions; automated auditory brainstem response

In the Netherlands, as in most Western countries, the prevalence of moderate to very severe bilateral congenital hearing loss in newborns is about one per thousand. ${ }^{1}$ Early detection of deafness or severe hearing loss, followed by early intervention, is important for optimal development, especially of language, speech, and cognitive abilities. Intervention started before the age of six months may result in better development of the child than intervention started later. ${ }^{2-6}$ Recently two screening methods that can be used shortly after birth have become widely available: automated auditory brainstem response testing (AABR) and automated testing with evoked otoacoustic emissions (OAE). Neonatal screening has many advantages. Such a programme would not cost much more than the current screening programme based on a distraction test ${ }^{1}$ and has been shown to increase the number of hearing impaired children managed early. ${ }^{7}$ It is therefore widely recommended. ${ }^{8}$

In most countries, neonatal hearing screening is implemented in hospital after the birth. In the Netherlands, however, most children are born at home or leave hospital within 16 hours of birth, making this unfeasible. In other countries, there is a trend towards earlier discharge after delivery, which affects the coverage of hospital based screening programmes. When high coverage is required, community based screening programmes may have to be considered in more countries in the future.

This study aims to compare the costs of different ways in which a community based universal programme of neonatal hearing screening can be implemented. Comparisons are made of the costs of the following aspects: the type of screening method used (OAE or AABR), the aim of the screening (detecting only bilateral hearing losses or unilateral losses also), the number of screening stages used, and the location of screening (at home or at a child health clinic (CHC)).

\section{Methods}

We calculated the costs of the screening programme itself, including the costs of all diagnostic testing, but excluding costs (and benefits) of treatment, counselling, and management of the cases detected. Calculations are based on the situation in the Netherlands, where a targeted neonatal hearing screening of all children in neonatal intensive care units, covering about $2 \%$ of all neonates, is already in place. Therefore only benefits to the population exclusive of these children are considered. As about a quarter of hearing impaired children are admitted to a neonatal intensive care unit, the costs per child detected would be a quarter lower if screening in the neonatal intensive care unit was not performed. Costs are calculated from the perspective of the health care financiers. Costs to society are partly examined in calculating the average time parents spend participating in the screening 


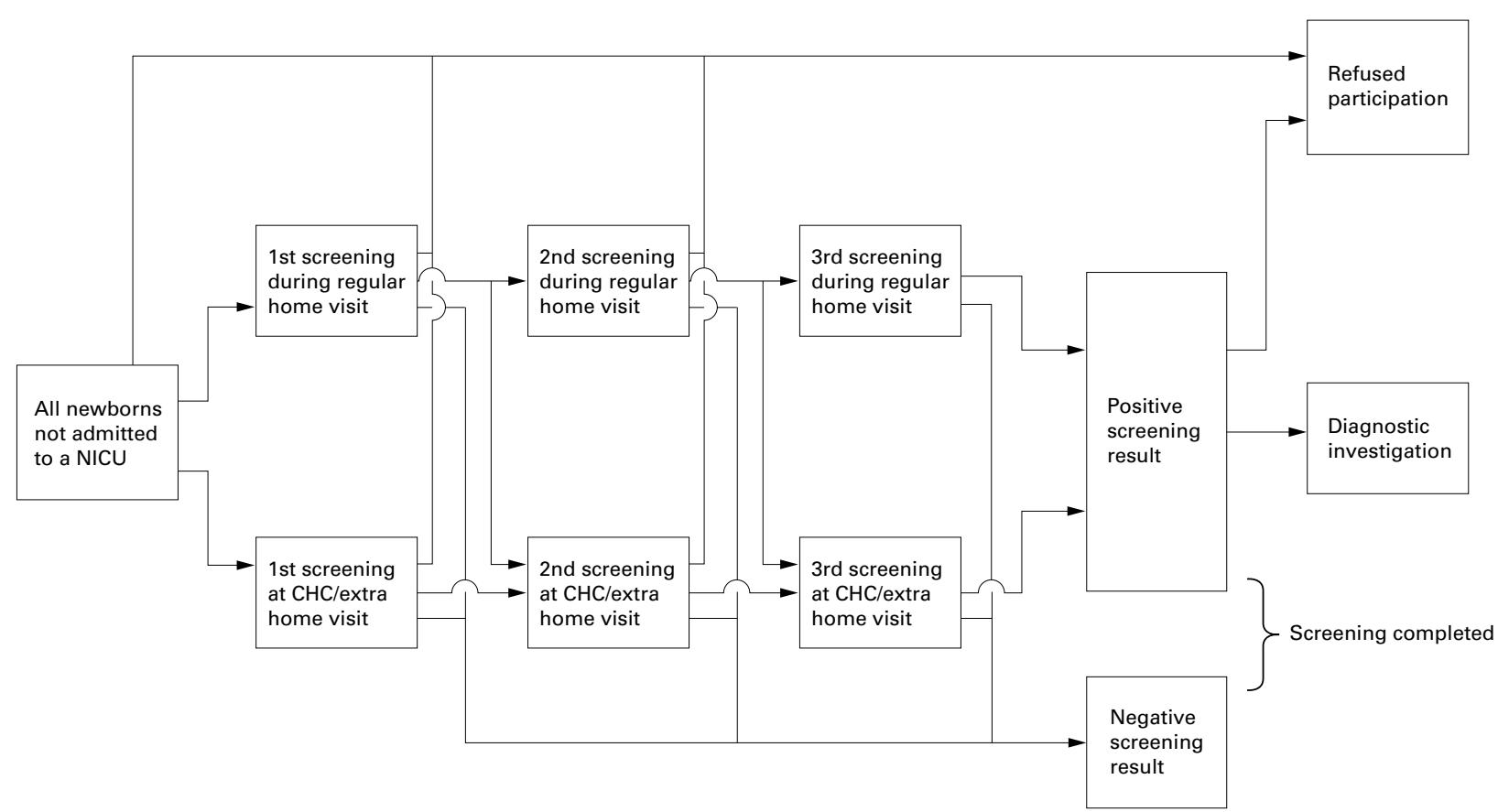

Figure 1 Flow through diagram of the screening programme as used in the model. The upper stream represents cases in which the hearing screening could be combined with a regular home visit. The lower stream represents activities carried out only because of the hearing screening. In some variants only the lower stream was used. NICU, Neonatal intensive care unit; CHC, child health clinic.

programme. The costs calculated are those of a programme that is already running.

The following elements of the screening programme were varied:

(1) The screening method (AABR or OAE). Calculations are based on the use of the most suitable commercially available equipment: the ALGO 1E from Natus Medical Inc (San Carlos, California, USA) (AABR) and the EchoCheck from OtoDynamics Ltd (Hatfield, Herts, UK) (OAE).

(2) The number of stages (two or three). Two stage screening procedures are customary, but have high false positive rates, especially when using OAE.

(3) The target disorder. The current screening programme in the Netherlands aims to detect both bilateral and unilateral hearing losses. As the benefits of early detection of children with unilateral hearing loss are unclear, we also calculated costs for finding only bilateral hearing loss. In this case, only one ear needs to be screened in most cases; only when this ear fails to respond is the second ear screened.

(4) Location-home or the CHC. Screening is more likely to be successful when performed at home than at the $\mathrm{CHC}$ because an infant is more likely to be peaceful or sleeping in this environment, and screening can more often be performed at an earlier age when the child is in this state. ${ }^{910}$ On the other hand, making home visits exclusively for neonatal hearing screening is time consuming and thus expensive. Therefore we only studied home visits that could be combined with existing home visits from health care workers during the first weeks of life-for example, for sampling of blood for phenylketonuria/congenital hypothyroidism screening or the CHC intake visit. When a combined visit was not possible, we assumed that screening took place during a special home visit or that the parents were invited to a screening session at the $\mathrm{CHC}$ (fig 1).

We varied the alternatives, starting from a central variant close to the situation tested in earlier feasibility studies $^{10-13}$ which looked promising at first sight. The central variant is two stage screening at the $\mathrm{CHC}$ by the $\mathrm{CHC}$ nurse, aimed to detect children with both unilateral and bilateral hearing losses. We then changed the factors listed above one by one.

The outcome measures calculated were:

- cost per child screened;

- cost per child detected with a hearing loss of $40 \mathrm{~dB}$ or more in the better ear;

- percentage of children referred for further diagnostic testing;

- positive predictive value of a positive screening result (at the end of the two or three stage screening programme) for hearing loss of $40 \mathrm{~dB}$ or more in the better ear;

- the average time parents spent attending the screening programme and further diagnostic testing (assuming only one parent attends).

Attendance rates were estimated from experience with the phenylketonuria/ congenital hypothyroidism screening, ${ }^{14}{ }^{15}$ current infant hearing screening, and previous feasibility studies in the Netherlands. ${ }^{10-13}$ Costs of equipment and consumables were based on quotes from the importers, assuming that 350 devices would be purchased. We assumed that equipment would be replaced on average every five years, which is relatively short because of continuing technical developments in this field. Hourly rates for the CHC nurses were based on national norms ${ }^{16}$ previous research into the costs of child health care ${ }^{17}$ the collective labour agreement for the $\mathrm{CHC}$, and the calculation method for costs of home care used by the National Health Tariffs Authority. 
Table 1 Costs and other outcomes of neonatal hearing screening (two stage screening with OAE) with various forms of organisation

\begin{tabular}{|c|c|c|c|c|c|c|}
\hline \multirow[b]{2}{*}{ Method } & \multirow{2}{*}{$\begin{array}{l}\text { Central variant } \\
\text { OAE }\end{array}$} & \multicolumn{5}{|c|}{ Variations on central variant } \\
\hline & & AABR & OAE & OAE & OAE & OAE \\
\hline Number of stages & 2 & 2 & 3 & 2 & 2 & 2 \\
\hline Aim & \multicolumn{3}{|c|}{$\begin{array}{l}\text { Detection of both unilateral and bilateral losses } \\
\text { (screening of both ears) }\end{array}$} & $\begin{array}{l}\text { Detection of } \\
\text { bilateral } \\
\text { losses only }\end{array}$ & \multicolumn{2}{|c|}{$\begin{array}{l}\text { Detection of both unilateral and } \\
\text { bilateral losses (screening of both } \\
\text { ears) }\end{array}$} \\
\hline Place of screening & $\mathrm{CHC}$ & $\mathrm{CHC}$ & $\mathrm{CHC}$ & $\mathrm{CHC}$ & $\begin{array}{l}\text { Home visits } \\
\text { only }\end{array}$ & $\begin{array}{l}\text { Home visit }+ \\
\text { CHC }\end{array}$ \\
\hline Costs per child screened (in $€$ ) & $20.9(2.3)$ & $29.4(3.0)$ & $18.1(1.7)$ & $17.0(1.9)$ & $23.7(2.9)$ & $20.1(2.1)$ \\
\hline $\begin{array}{l}\text { Costs per child detected (NICU screening in place) (in } \\
1000 € \text { ) }\end{array}$ & $29.0(6.4)$ & $40.7(9.4)$ & $25.0(5.4)$ & $23.5(5.9)$ & $32.1(8.2)$ & $27.4(6.0)$ \\
\hline$\%$ referred for diagnostic testing & $3.6(1.0)$ & $2.3(0.6)$ & $1.8(0.6)$ & $2.2(0.8)$ & $2.0(0.8)$ & $2.4(0.9)$ \\
\hline Positive predictive value (NICU screening in place) (\%) & $2.2(0.7)$ & $3.5(1.1)$ & $4.5(1.6)$ & $3.6(1.4)$ & $3.9(1.7)$ & $3.3(1.4)$ \\
\hline Time spent by parent (hours) & $1.2(0.1)$ & $1.2(0.1)$ & $1.2(0.1)$ & $1.1(0.1)$ & $0.4(0.05)$ & $0.4(0.07)$ \\
\hline
\end{tabular}

The elements printed in bold differ from the central variant. Values are mean (SEM).

OAE, Otoacoustic emissions; AABR, automated auditory brainstem response; CHC, child health clinic; NICU, neonatal intensive care unit.

Cost of sending out invitations, making appointments, training, a central helpdesk, and monitoring of the programme were based on experience from current infant hearing programmes and phenylketonuria/congenital hypothyroidism screening programmes.

A multivariate sensitivity analysis was performed using Monte-Carlo simulation. The standard error in the outcomes was determined from 500 simulations.

\section{Results}

Table 1 shows that the costs of screening with $\mathrm{AABR}$ are appreciably higher than screening with OAE, a conclusion upheld by the sensitivity analysis. Table 2 shows that this is mainly due to the costs of the consumables (disposable earcoupler and electrodes) used with the ALGO 1E. It has been suggested that it is possible to economise by reusing these consumables, but even then AABR would be more expensive because of the higher costs of the equipment despite its higher specificity, which reduces the costs of further diagnostic testing. When the time parents have to invest is considered, however, the extra time involved in using AABR is easily outweighed by the reduction in time necessary for further diagnostic testing. When the total equipment related costs (depreciation and consumables) are left out, OAE screening costs $€ 18.2$ per infant screened and AABR screening $€ 17.2$. Three stage screening has lower costs than two stage screening, as a third stage only slightly increases the costs of the screening itself, but greatly reduces the costs of further diagnostic testing (table 2).

Screening for bilateral hearing loss reduces both the costs per infant screened and the number of referrals for further diagnostic testing. Such screening, however, will not detect most children with unilateral hearing loss. On the basis of limited data available, ${ }^{18-21}$ we estimate that the number of newborn infants with unilateral hearing loss is up to twice the number with bilateral hearing loss. Thus the cost per child detected with unilateral or bilateral hearing loss will be up to three times lower than the cost given in tables 1 and 3, and the extra cost of detecting a child with unilateral hearing loss (over and above the cost of a screening programme aimed at detecting only bilateral losses) is roughly $€ 1500-4000$.

The sensitivity analyses showed that the cost of a two stage OAE screening programme taking place at the CHC does not significantly differ from the cost when such screening takes place during combined home visits when possible, and at the CHC otherwise. However, the percentage of children referred for further diagnostic testing is lower and the time parents have to spend is less in the variant with home visits. These differences are confirmed by the sensitivity analysis.

As three stage screening is probably preferable to two stage screening, table 3 presents all possible variants with three stage screening. Again screening using OAE costs less than screening using AABR, but has a lower positive

Table 2 Breakdown of the costs per child screened for the variants in table 1 (in €)

\begin{tabular}{|c|c|c|c|c|c|c|}
\hline \multirow[b]{2}{*}{ Method } & \multirow{2}{*}{$\begin{array}{l}\text { Central variant } \\
\mathrm{OAE}\end{array}$} & \multicolumn{5}{|c|}{ Variations on central variant } \\
\hline & & AABR & OAE & OAE & OAE & OAE \\
\hline Number of stages & 2 & 2 & 3 & 2 & 2 & 2 \\
\hline Aim & \multicolumn{3}{|c|}{$\begin{array}{l}\text { Detection of both unilateral and bilateral losses (screening of } \\
\text { both ears) }\end{array}$} & $\begin{array}{l}\text { Detection of } \\
\text { bilateral losses }\end{array}$ & \multicolumn{2}{|c|}{$\begin{array}{l}\text { Detection of both unilateral and } \\
\text { bilateral losses (screening of both ears) }\end{array}$} \\
\hline Place of screening & $\mathrm{CHC}$ & $\mathrm{CHC}$ & $\mathrm{CHC}$ & $\mathrm{CHC}$ & $\begin{array}{l}\text { Home visits } \\
\text { only }\end{array}$ & $\begin{array}{l}\text { Home visit + } \\
\text { CHC }\end{array}$ \\
\hline Personnel & 7.3 & 8.9 & 7.5 & 5.9 & 11.5 & 8.0 \\
\hline Depreciation of equipment & 2.3 & 4.3 & 2.3 & 2.3 & 3.0 & 3.0 \\
\hline Consumables/repairs & 0.5 & 7.9 & 0.5 & 0.5 & 0.5 & 0.5 \\
\hline Extra travel costs of personnel & 0.0 & 0.0 & 0.0 & 0.0 & 0.7 & 0.0 \\
\hline Cost of invitations & 2.2 & 2.0 & 2.2 & 2.0 & 1.6 & 1.6 \\
\hline Costs of training & 1.5 & 1.3 & 1.5 & 1.5 & 2.0 & 2.0 \\
\hline Helpdesk/monitoring & 1.1 & 1.1 & 1.1 & 1.1 & 1.1 & 1.1 \\
\hline Diagnostic testing & 6.1 & 3.8 & 2.9 & 3.7 & 3.4 & 3.9 \\
\hline Total & 20.9 & 29.4 & 18.1 & 17.0 & 23.7 & 20.1 \\
\hline
\end{tabular}

The elements printed in bold differ from the central variant.

OAE, Otoacoustic emissions; AABR, automated auditory brainstem response; $\mathrm{CHC}$, child health clinic. 
Table 3 Costs per child detected with a bilateral hearing loss $\geqslant 40 \mathrm{~dB}{ }^{\star}$ and positive predictive value for a hearing loss $\geqslant 40 \mathrm{~dB}$ in the better ear ${ }^{*}$ for three stage screening procedures

\begin{tabular}{|c|c|c|}
\hline & $\begin{array}{l}\text { Cost per child detected with } \\
\text { bilateral hearing loss } \geqslant 40 \mathrm{~dB} \\
\text { (in } 1000 €)\end{array}$ & $\begin{array}{l}\text { Positive predictive value for } \\
\text { bilateral hearing loss } \geqslant 40 \mathrm{~dB} \\
\text { (in \%) }\end{array}$ \\
\hline \multicolumn{3}{|c|}{ Detecting both unilateral and bilateral hearing loss (screening both ears)* } \\
\hline \multicolumn{3}{|c|}{ OAE } \\
\hline Only home visits & $30.5^{\star}$ & $8.6^{\star}$ \\
\hline Only at $\mathrm{CHC}$ & $25.0^{\star}$ & $4.5^{\star}$ \\
\hline Home visits backed up by screening at $\mathrm{CHC}$ & $24.9^{\star}$ & $6.8^{\star}$ \\
\hline \multicolumn{3}{|l|}{ AABR } \\
\hline Only home visits & $43.8^{\star}$ & $14.6^{\star}$ \\
\hline Only at $\mathrm{CHC}$ & $38.5^{\star}$ & $7.1^{\star}$ \\
\hline Home visits backed up by screening at $\mathrm{CHC}$ & $39.1^{\star}$ & $11.8^{\star}$ \\
\hline \multicolumn{3}{|c|}{ Detecting only bilateral hearing loss (mainly screening only one ear) $\dagger$} \\
\hline \multicolumn{3}{|c|}{ OAE } \\
\hline Only home visits & 25.1 & 24.0 \\
\hline Only at $\mathrm{CHC}$ & 21.6 & 6.2 \\
\hline Home visits backed up by screening at $\mathrm{CHC}$ & 21.3 & 16.4 \\
\hline
\end{tabular}

*Although children with both unilateral and bilateral losses will be detected, outcomes are based only on detecting children with bilateral hearing loss.

†No data could be found on the failure rates per ear in AABR screening. Therefore no results are given for AABR screening. OAE, Otoacoustic emissions; AABR, automated auditory brainstem response; $\mathrm{CHC}$, child health clinic.

predictive value. Screening at home has a higher positive predictive value than screening in the CHC. Screening with OAE aimed at detection of both unilateral and bilateral hearing loss yields rather low positive predictive values, even in the most favourable cases. Some of the false positives, however, will be children with mild hearing loss (less than $40 \mathrm{~dB}$ in the better ear).

\section{Discussion}

In this study we compared the cost of finding a child with bilateral hearing loss using different screening programmes (cost comparison), but we did not carry out a full cost effectiveness study of neonatal hearing screening. After all, the implications in terms of costs and benefits are identical for each child detected, regardless of the method, and therefore it is not necessary to calculate full cost effectiveness of each programme to decide on the most cost effective programme. However, this reasoning rests on two assumptions that may be disputed. The first is that the number of cases missed by the programmes (which could be at considerable human and social cost) is comparable in each programme. Cases missed can be due to non-compliance (of parents or doctors) with the screening programme, or to false negative test results. The non-compliance was estimated (based on compliance in other neonatal screening programmes) to vary between $1.1 \%$ and $3.5 \%$ in the different screening programmes, and was mainly determined by whether the screening included home visits or not. The number of false negatives may depend on the method used (OAE or AABR). To date, however, data on the false negative rates of these methods are almost absent, as such data require follow up experience of tens of thousands of screened children. For children admitted to neonatal intensive care units, $\mathrm{AABR}$ is more sensitive, both theoretically and based on case reports, ${ }^{22}$ as it also detects hearing loss generated in the pathway between the cochlea and the brainstem. However, this type of hearing loss is probably extremely rare in children who have not been admitted to neonatal intensive care units. The second assumption is that all programmes detect the children early enough. Introducing a third screening stage or postponing screening until the child is old enough to visit a $\mathrm{CHC}$ would cause some delay. However, when the screening is well organised, these delays should not prevent detection before the age of 3 months.

Our approach is mainly financial, and therefore aspects such as the emotional cost to parents of false positive results or the detrimental consequences of false reassurance in the case of a false negative are not included. However, such arguments are important in deciding which programme should be implemented.

The calculations presented here are based on the situation in the Netherlands, which in many respects (price of equipment and consumables, price of labour) is similar to that in the rest of Western Europe. The most relevant aspect is probably the high population density of the Netherlands, making travelling distances relatively short. Nevertheless, in most countries there are large urbanised regions that are as densely populated as the Netherlands.

Screening with AABR with current equipment (ALGO 1E, requiring costly consumables) is more expensive than screening with automated OAE, but has lower referral rates. Therefore, at present, AABR can only be recommended when the benefit of lower referral rates is judged to be very important or when AABR is judged to have a significantly higher sensitivity.

The cost of screening for bilateral hearing loss only is lower than the cost of screening for unilateral loss also, but such screening will miss most infants with unilateral hearing loss. The value of detecting children with unilateral hearing loss is controversial, as there is no compelling evidence that early detection leads to a relevant gain in health and development. We showed that the extra cost of detecting a child with unilateral hearing loss (over and above the cost of a screening programme aimed at detecting only bilateral loss) is roughly $€ 1500-4000$. It is a matter of opinion whether it is worth paying this price. In the Netherlands it was decided to include screening on 
unilateral losses in further implementation studies.

Screening at home during the first two weeks of life results in lower referral rates than screening at a CHC three weeks later. Whether screening at home is also financially opportune remains to be seen. Further field experiments will have to decide this issue.

In England a cost of $£ 13.9$ (about $€ 23$ ) per child screened was calculated for a universal programme of neonatal hearing screening, ${ }^{23}$ which is within the range we calculated for a two stage OAE based screening programme, but lower than a two stage ABR based screening programme. In the United States, the cost of a screening programme using $\mathrm{OAE}$ in the first stage and AABR in the second stage was estimated to be $\$ 26.05$ (about $€ 30$ ) per child screened, ${ }^{24}$ and that of a screening programme using AABR to be $\$ 17$ (about $€ 20$ ). ${ }^{25}$ Our estimates for two stage screening programmes lie between these two findings. So, despite the fact that in our community based screening programme more equipment is needed (about one screening device per 500 children born annually), screening can be performed at costs similar to those calculated for these programmes in the United Kingdom and United States. We speculate that, in the CHC model, better use can be made of the time of personnel because appointments can be planned more effectively in the larger time window available for the screening.

The calculations show that three stage screening seems to be more cost effective than two stage screening. It also lowers the referral rates and thus increases the positive predictive value of a positive screening result. This conclusion depends heavily on the percentage of children assumed to have a negative screening result in the third stage, which, because of a lack of empirical data, is based on an informed guess. According to our calculations, diagnostic testing costs about 13 times as much as screening at a $\mathrm{CHC}$, so third stage screening will be cost effective when more than one of 13 children have a negative screening result in the third stage, which seems realistic.

In conclusion, we recommend three stage screening with OAE. Whether screening at home is more cost effective than screening at a $\mathrm{CHC}$ needs further study.

The study was funded by the Netherlands Prevention Fund, currently merged with the Health Research and Development currently merged with the Herl of the Netherlands
Council

1 Verkerk PH, Boshuizen HC. Health economic analysis: cost-effectiveness of the infant distraction test and neonatal hearing screening in the Netherlands. European consensus development conference on neonatal hearing screening, Milano, development conference on neonatal hearing screening, Milano, neering, 1998.
2 Davis A, Bamford J, Wilson I, et al. A critial review of the role of neonatal hearing screening in the detection of congenital hearing impairment. Health Technol Assess 1997;1:1-176.

3 Yoshinaga-Itano C, Sedey AL, Coulter DK, et al. Language of early- and later-indentified children with hearing loss. Pediatrics 1998;102:1161-71.

4 Markides R. Age of fitting of hearing aids and speech intelligibility. Br F Audiol 1986;20:165-7.

5 Ramkalawan TW, Davis AC. The effects of hearing loss and age of intervention on some language metrics in young hearing-impaired children. Br f Audiol 1992;26:97-107.

6 Eilers RE, Oller DK. Infant vocalizations and the early diagnosis of severe hearing impairment. 7 Pediatr 1994;124:199-203.

7 Wessex Universal Neonatal Hearing Screening Trial Group. Controlled trial of universal neonatal screening for early identification of permanent childhood hearing impairment. Lancet 1998;352:1957-64.

8 Lutman ME, Grandori, F. Screening for neonatal hearing defects European consensus statement. Eur $\mathcal{F}$ Pediatr 1999;158:95-6.

9 Van Kerschaver E. Early hearing screening in a programme of evidence-based preventive medicine. EUSUHM congress September 1997. Leuven: Vlaamse Wetenschappelijke Vererniging voor Jeugdgezondheidszorg, 1997.

10 Zanten GA van, Lem GJ van der, Mülder HE, et al. Gehoorscreening met otoakoestische emissies bij pasgeborenen binnen de jeugdgezondheidszorg. Amsterdam/Rotterdam: Nederlands jeugdgezondheidszorg. Amsterdam/Rotterdam: Nederlands Stichting voor het Dove en Slechthorende
Universiteit/Sophia Kinderziekenhuis, 1995.

11 Oudesluys-Murphy AM, Harlaar J. Neonatal hearing screening with an automated auditory brainstem response screener in the infant's home. Acta Paediatr 1997;86:651-

12 Harlaar J, Oudesluys-Murphy AM. Neonatale gehoorscreening binnen de reguliere zuigelingenzorg. Tijdschr feugdgezondheidsz 1997;29:8-11.

13 Lem GJ van der, Kauffman-de Boer MA, Netten-Wijnands YHHM, et al. Neonatale gehoorscreening binnen de jeugdgezondheidszorg. Een experiment. Amsterdam/Uden: Nederlands Stichting voor het Dove en Slechthorende Kind/ Stichting thuiszorg Brabant Noord-Oost, 1998.

14 Verkerk PH. 20-year national screening for phenylketonuria in The Netherlands. National Guidance Commission PKU. Ned Tijdschr Geneeskd 1998;139:2302-5.

15 Verkerk PH, Derksen-Lubsen G, Vulsma T, et al. Evaluation of a decade of neonatal screening for congenital hypothyroidism in The Netherlands. Ned Tijdschr Geneeskd 1993;137:2199-205.

16 Burgmeijer RJF. Zorgpakket ouder- en kindzorg; Inhoud en achtergronden van de ouder- en kindzorg. Beleidsnota: Bunnik. Landelijke Vereniging voor Thuiszorg, 1995.

17 Burgmeijer RJF, Geenhuizen YMv, Filedt-Kok-Weimar TL, et al. Op weg naar volwassenheid. Evaluatie jeugdgezondheidszorg 1996. Leiden/Maarssen: TNO Preventie en Gezondheid /KPMG, 1997

18 Maxon $\mathrm{AB}$, White $\mathrm{KR}$, Vohr $\mathrm{BR}$, et al. Using transient evoked otoacoustic emissions for neonatal hearing screening. Br F Audiol 1993;27:149-53.

19 Norton SJ, Vohr B, Gorga MP, et al. A comparison of the effectiveness of three neonatal hearing screening procedures: auditory abrainstem responses (ABR), transient evoked otoacoustic emissions (TEOAE) and distortion product otoacoustic emissions (DPOAE) [abstract]. Pediatrics 1998;102:766.

20 Brookhouser PE. Sensorineural hearing loss in children. Pediatr Clin North Am 1996;43:1195-216.

21 Mehl AL, Thomson V. Newborn hearing screening: the great omission. Pediatrics 1998;101:E4.

22 Psarommatis IM, Tsakanikos MD, Kontorgianni AD, et al. Profound hearing loss and presence of click-evoked otoacoustic emissions in the neonate: a report of two cases. Int 7 Pediatr Otorhinolaryngol 1997;39:237-43.

23 Stevens JC, Hall DMB, Davis A, et al. The costs of early screening in England and Wales. Arch Dis Child 1998;78:14-9

24 Mason JA, Herrmann KR. Universal infant hearing screening by automated auditory brainstem response measurement. Pediatrics 1998;101:221-8.

25 Maxon AB, White KR, Behrens TR, et al. Referral rates and cost efficiency in a universal newborn hearing screening programme using transient evoked otoacoustic emissions. f Am Acad Audiol 1995;6:271-7. 